\title{
Perfil microbiológico dos pacientes nos primeiros trinta dias pós transplante de medula óssea do Serviço de T ransplantes da Santa Casa de São Paulo
}

Flávio A. Naoum ${ }^{1}$

Larissa T. V. Martins ${ }^{1}$

Nelson S. Castro

José C. Barros ${ }^{2}$

Carlos S. Chiattone ${ }^{3}$
As infecções bacterianas continuam sen do uma das principais causas de morbidade e mortalidade nos pacientes transplantados de medula óssea. 0 período de neutropenia, que compreen de os primeiros trinta dias do tratamento, éo maisvulnerável em relação àsinfecçõesbacterianas. A melhora na cobertura antibiótica tem alterado a incidência e prevalência dosagentes bacterianos nas últimas décadas. 0 uso de culturas de vigilância é uma estratégia usada no sentido de identificar um agente capaz de ocasionar morbidade importante nesta fase do tratamento. Entretanto, sua utilização sistemática é criticada no sentido de sua baixa sensibilidade e especificidade. Os autores avaliaram as culturas de vigilância de 50 pacientes nos primeiros 30 dias de transplante do Serviço de Hematologia e Hemoterapia da Santa Casa de São Paulo. Os indivíduos do sexo masculino compreenderam $62 \%$ da amostra, sen do o transplante alogênico e de células tronco periférica $68 \%$ e $72 \%$ respectivamente. A faixa etária prevalente foi de 21 a 40 anos. A leucemia mielóide crônica foi a indicação mais freqüente de transplante. Os agentes Gram positivos foram isolados em $64 \%$ das culturas. 0 local de prevalência de culturas por bactérias Gram positivas ocorreu em pele, região nasal edeinserção decateter eGram negativosem região perianal. A avaliação retrospectiva não mostrou relação das culturas de vigilância com a alteração do esquema antibiótico ou à presença de hemoculturas positivas no período. Rev.bras.hematol.hemoter.,2002,24(2):91-96

Palavras-chave: Transplante de medula óssea, culturas de vigilância,infecção

\section{Introdução}

O transplante de medula óssea é uma modalidade terapêutica que vem sendo cada vez mais usada no tratamento de doenças hematológicas malignas e não-malignas, tumores sólidos e doenças genéticas e metabólicas.
Infecção e a doença enxerto contra hospedeiro continuam sendo a principal causa de morbidade e mortalidade nestes pacientes. 0 período de neutropenia, que em geral compreende os primeiros 30 dias de internação, é o de maior vulnerabilidade à estas complicações (1).

As infecções bacterianas predominam no

1 - Médicos aperfeiçoando da Disciplina de Hematologia e Oncologia da Faculdade de Ciências Médicas da Santa Casa de São Paulo e do Hemocentro da Santa Casa de São Paulo

2 - Professores assistentes da Disciplina de Hematologia e Oncologia da Faculdade de Ciências Médicas da Santa Casa de São Paulo e do Hemocentro da Santa Casa de São Paulo

3 - Chefe da Disciplina de Hematologia e Oncologia da Faculdade de Ciências Médicas da Santa Casa de São Paulo e do Hemocentro da Santa Casa de São Paulo

Correspondência para: Flávio Augusto Naoum

Hemocentro da Santa Casa de São Paulo

Rua Marquês de Itu, $579-2^{\circ}$ andar. CEP: 01223-001. São Paulo. SP

Telefone: (11) 3226-7259. E-mail: cehemato@santacasasp.org.br 
período de neutropenia e seu perfil vem sofrendo alterações devido a vários fatores, como o emprego de antibióticos mais efetivos e à melhora das condicões de suporte. Houve, como conseqüência, mudança em relação aos agentes etiológicos das infecções bacterianas, com predomínio das infecções causadas por bactérias gram positivas em relação aos germes gram negativos (1).

Esforços no sentido de diminuir o risco de contaminação incluem normas rígidas em relação à higiene da equipe que assiste ao paciente, cuidados com dieta e água do paciente, isolamento em quarto com fluxo de ar laminar e realização de culturas de vigilância. Embora apresentem papel controverso e custo elevado, para alguns autores as culturas de vigilância são essenciais para detectar aquisição de germes resistentes e possibilitar ajustes na profilaxia com antibióticos (2).
O objetivo deste estudo é analisar o perfil microbiológico dos pacientes submetidos ao transplante de medula óssea nos primeiros 30 dias de internação.

\section{$M$ ateriais e $M$ étodos}

Analisamos, retrospectivamente, os prontuários de 50 pacientes submetidos a transplante de medula óssea no período de outubro de 1993 a maio de 2001. Foram coletados dados gerais dos doentes como sexo, idade à época do transplante, tipo de doença, tipo de transplante (alogênico ou autogênico), fonte de células (medula óssea ou células-tronco periféricas), tempo decorrido do diagnóstico ao transplante de medula e óbitos ocorridos no período (Tabela 1).

Tabela 1 Características dos pacientes quanto a sexo, tipo de transplante, fonte de células para transplante, faixa etária, indicações de transplante, tempo de evolução da doença ao transplante e óbitos ocorridos no período.

\begin{tabular}{|l|l|l|}
\hline Sexo & Masculino & $31(62 \%)$ \\
& Feminino & $19(38 \%)$ \\
\hline Tipo de transplante & Alogênico & $39(78 \%)$ \\
& Autogênico & $11(22 \%)$ \\
\hline Fonte de células & Células-Tronco Periféricas & $43(86 \%)$ \\
& Medula óssea & $07(14 \%)$ \\
\hline Faixa etária & Até 20 anos & $12(24 \%)$ \\
mediana: 31 anos & 21 a 40 anos & $26(52 \%)$ \\
\hline Indicações & $>40$ anos & $12(24 \%)$ \\
\hline de transplante & Leucemia Mielóide Crônica & $20(37 \%)$ \\
& Leucemia Linfóide Aguda & $09(17 \%)$ \\
& Leucemia Mielóide Aguda & $05(10 \%)$ \\
& Anemia Aplástica Severa & $05(10 \%)$ \\
& Mieloma Mútltiplo & $04(08 \%)$ \\
& Linfoma de Hodgkin & $02(08 \%)$ \\
& Linfoma Não-Hodgkin & $02(04 \%)$ \\
\hline Mediana do tempo evolução do diagnóstico & $02(04 \%)$ \\
ao transplante & Síndrome Mielodisplásica & $01(02 \%)$ \\
\hline Óbitos ocorridos nos primeiros 30 dias de internação & 19 meses \\
\hline
\end{tabular}


Também analisamos o período de febre durante a primeira internação. Os óbitos ocorridos nos primeiros 30 dias de transplante de medula óssea (TMO) e suas prováveis causas foram analisados pelo laudo da necropsia e anotações no prontuário.

Apenas um paciente realizou radioterapia como parte do condicionamento, os demais foram condicionados somente com quimioterapia. Nenhum paciente recebeu antibiótico via oral não-absorvível para descontaminação do trato gastro-intestinal ou profilaxia com antibiótico absorvível, e apenas quatro pacientes foram internados em quartos com fluxo de ar laminar. Todos os pacientes portavam cateter de Hickman por ocasião do transplante.

$\mathrm{Na}$ enfermaria de TMO do Hospital Central da Santa Casa de São Paulo (HCSC), para estudo da colonização ou infecção dos pacientes por agentes infecciosos, foram colhidos de rotina e uma vez por semana os seguintes exames: hemocultura, urocultura, coprocultura e swab de cavidade nasal, axila, inserção de cateter, glande, vagina e ânus.

Todos os pacientes receberam dieta apropriada para neutropênicos. No período de neutropenia, definido quando a contagem absoluta de neutrófilos estava abaixo de $1.000 / \mathrm{mm}^{3}(10)$, todos os pacientes receberam cobertura antibiótica profilática com ceftazidime ou cefepime.

O perfil microbiológico dos pacientes foi obtido mediante análise do número de positividades nas culturas quanto ao agente infeccioso identificado, e em relação ao material coletado (sangue, inserção de cateter, urina, fezes, escarro, e swabs de orofaringe, axila, cavidade nasal, glande, vagina e ânus). Todas as culturas positivas foram analisadas conjuntamente, tanto as de rotina como aquelas realizadas na vigência de febre (temperatura axilar igual ou superior a $37,8^{\circ} \mathrm{C}$ ) ou colhidas fora da rotina por motivo de infecção ou alteração do quadro clínico do paciente. Somente os dados dos primeiros 30 dias de internação pós TMO foram coletados.

Todas as culturas obtidas foram analisadas no Laboratório de Microbiologia do HCSC. As hemoculturas foram realizadas pelo método semiautomático e as demais culturas por meio de esfregaços, utilizando principalmente ágar sangue, ágar chocolate, agar MacConkey, ágar XLD (coprocultura) e ágar Sabouraud (na pesquisa de fungo).

\section{Resultados}

O grupo estudado foi caracterizado pela prevalência do sexo masculino, mais da metade dos pacientes na faixa dos 21 aos 40 anos, sendo LMC a indicação mais freqüente de transplante (37\%). A maioria dos transplantes realizados foi alogênica, utilizando principalmente células-tronco periféricas como fonte.

Durante os primeiros 30 dias de internação, ocorreram 15 óbitos ( 13 nos pacientes que receberam TMO alogênico e 2 nos que receberam TMO autogênico), sete deles por provável causa infecciosa, seis em conseqüência de hemorragia, um por distúrbio metabólico grave e um devido à edema agudo de pulmão.

Q uarenta e sete pacientes (94\%) tiveram febre documentada na primeira internação, iniciando no oitavo dia do TMO e apresentando mediana de sete dias.

Um total de 448 agentes infecciosos foi identificado pela análise de todas as culturas realizadas no grupo estudado. Estas positividades foram analisadas em relação ao material coletado e aos agentes infecciosos mais freqüentemente encontrados (gráficos 1 e 2).

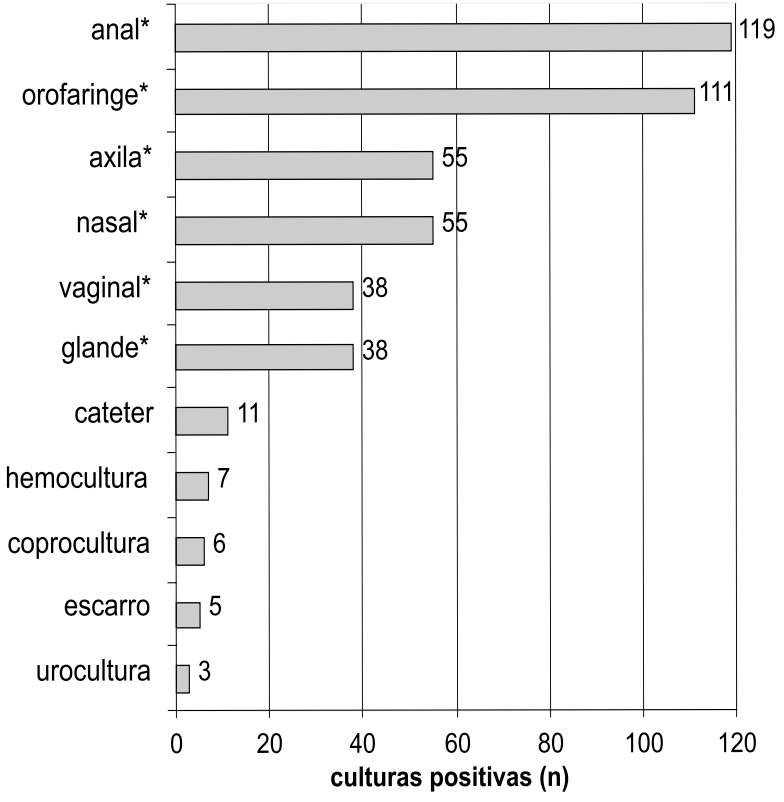

* - material coletado por meio de swab

Gráfico 1. Número de positividades nas culturas em relação ao material coletado 


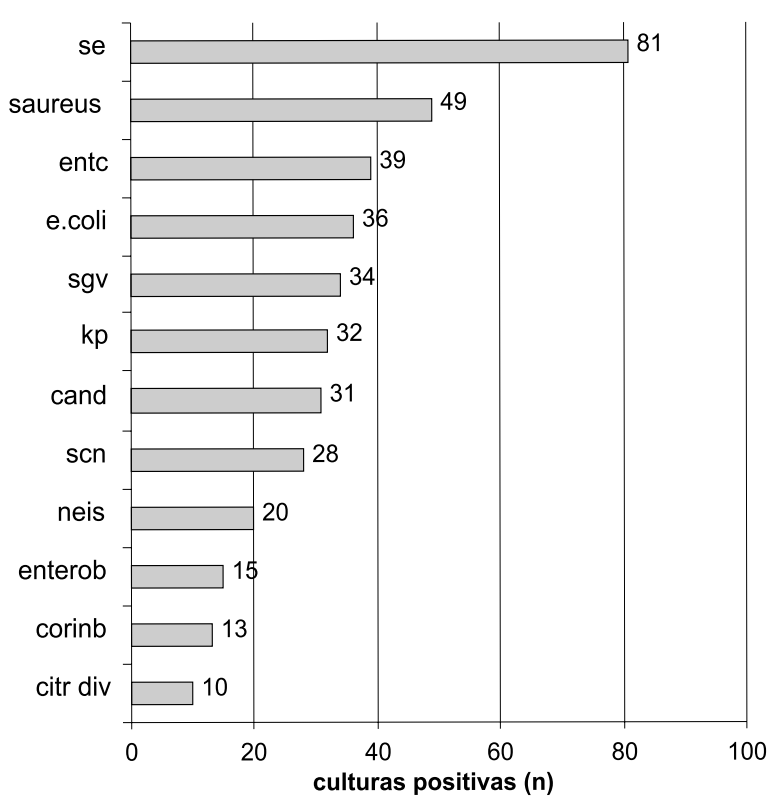

se-Streptococcus epidermidis; saureusStaphylococcus aureus; entc-Enterococcus spp; e.coli-Escherichia coli; sgv-Staphylococos do grupo viridans; kp-Klebsiella pneumoniae; cand-Candida albicans; scn-Staphylococcus coagulase negativo; neis-Neisseria sp; enterobEnterobacter spp; corinb-Coryn ebacterium spp; citr div-Citrobacter diversus

Gráfico 2. Número de positividades nas culturas em relação aos agentes infecciosos mais freqü entemente identificados (10 ou mais positividades)
Sete pacientes apresentaram hemoculturas positivas: duas para Cândida albicans, duas para Klebsiella pneumoniae, uma para Enterococcus spp, uma para Staphylococcus aureus e uma para Providencia sp. Os germes identificados nas hemoculturas foram determinantes na mudança do antibiótico e não tiveram relação com aqueles identificados nas culturas de vigilância realizadas no mesmo período (dados não apresentados).

As bactérias gram positivas foram responsáveis por 265 (64\%) positividades, e as bactérias gram negativas por 152 (36\%). A positividade destes dois grupos foi analisada nos diferentes locais de coleta (Tabela 2).

\section{D iscussão}

Dentre os óbitos documentados, 33\% deles ocorreram nos pacientes submetidos a TMO alogênico e $18 \%$ nos autogênicos, entretanto, apesar da observação na literatura de maior período de neutropenia e dias de hospitalização entre os pacientes que realizaram TMO alogênico, alguns autores não encontraram diferença significante da incidência de infecção neste grupo quando comparados aos transplantes autogênicos (3).

Buckner et al demonstraram a importância do fluxo de ar laminar (FAL) na diminuição do número de infecções e aumento na sobrevida dos

Tabela 2. Positividades de bactérias gram-positivas e gram-negativas nas culturas em relação ao material coletado

\begin{tabular}{|l|c|c|}
\hline Material coletado & Gram-positivos (\%) & Gram-negativos (\%) \\
\hline Swab anal & $53(44 \%)$ & $61(56 \%)$ \\
\hline Swab orofaringe & $65(66 \%)$ & $34(34 \%)$ \\
\hline Swab axila & $45(87 \%)$ & $07(13 \%)$ \\
\hline Swab nasal & $49(91 \%)$ & $05(09 \%)$ \\
\hline Swab vaginal & $18(50 \%)$ & $18(50 \%)$ \\
\hline Swab glande & $20(56 \%)$ & $16(44 \%)$ \\
\hline Cateter & $07(70 \%)$ & $03(30 \%)$ \\
\hline Hemocultura & $02(40 \%)$ & $03(60 \%)$ \\
\hline Coprocultura & $01(20 \%)$ & $04(80 \%)$ \\
\hline Escarro & $04(100 \%)$ & $0(0 \%)$ \\
\hline Urocultura & $01(50 \%)$ & $01(50 \%)$ \\
\hline Total & $\mathbf{2 6 5 ( 6 4 \% )}$ & $\mathbf{1 5 2}(\mathbf{3 6 \% )}$ \\
\hline
\end{tabular}


pacientes já foi demonstrada em estudos prévios (4). Assim, o fato da maioria dos pacientes (92\%) não terem sido submetidos ao FAL pode ter contribuído para o aumento do número de infecções e episódios febris no grupo como um todo. Os mesmos autores não observaram redução no número de infecções adquiridas entre os pacientes que realizaram descontaminação oral do trato gastro-intestinal (4).

Nos anos 70 e 80, pacientes neutropênicos eram mais freqüentemente colonizados e infectados por bacilos gram-negativos $(2,7)$. Na última década, entretanto, houve um declínio na incidência destas infecções, devido à melhora da antibioticoterapia para estes agentes, associado ao aumento da faixa etária dos pacientes e a resistência aos agentes beta lactâmicos (8). Do mesmo modo, notou-se uma mudança no perfil microbiológico dos agentes que causam infecção neste grupo de pacientes, com aumento das infecções estafilocócicas - principalmente àquelas atribuídas ao Staphylococcus epidermidis relacionadas ao uso permanente de cateter venoso central $(1,9)$

Nosso estudo demonstrou uma clara prevalência da colonização dos pacientes por bactérias gram-positivas (64\%), sendo $\mathrm{S}$. epidermidis o germe mais freqüentemente identificado, responsável por $18 \%$ do total de positividades e $30 \%$ das positividades entre os germes gram-positivos.

O maior número de positividades ocorreu nos swabs coletados da região anal e orofaringe dos pacientes ( $26 \%$ e $24 \%$ do total de positividades, respectivamente). Os locais colonizados principalmente pelas bactérias gram-positivas foram axila, região nasal, local de inserção do cateter e escarro. Os gram-negativos foram mais frequentes nas fezes principalmente. Estes dados são semelhantes aos descritos por Czirók e cols. que estudaram culturas de vigilância em 26 pacientes submetidos ao TMO e observaram maior incidência de bactérias gram-positivas, sendo pele, orofaringe, glande e vagina os locais de maior colonização (5).

Apesar dos nossos achados em relação às culturas de vigilância, observamos que estas raramente foram de valia na mudança ou introdução da antibioticoterapia, cujo principal parâmetro foi a febre (dado não documentado). Da mesma forma, durante a coleta dos dados, observou-se que as poucas hemoculturas positivas não apresentavam correlação com as positividades das culturas de vigilância. Bactérias com parede celular deficiente vêm sendo implicadas na baixa positividade das hemoculturas durante os episódios febris dos pacientes submetidos ao TMO (6).

Riley et al estudaram 48 pacientes que realizaram TMO e questionaram 0 papel das culturas de vigilância ao observarem baixa sensibilidade $(38 \%)$, especificidade $(25 \%)$, valor preditivo positivo (20\%) e valor preditivo negativo (20\%) em relação ao desenvolvimento das infecções documentadas no grupo (3). Baixa correlação entre culturas de vigilância positivas e infecções clinicamente documentadas também foi observada por outros autores (5). Entretanto, as culturas de vigilância podem ser úteis na investigação dos efeitos dos tratamentos profiláticos na seleção de germes resistentes, e auxiliar o estudo da epidemiologia da colonização nos pacientes netropênicos.

\section{Conclusão}

Ainda existe discussão à respeito da validade da realização das culturas de vigilância em relação ao benefício que um tratamento preemptivo possa preservar o paciente neutropênico de uma infecção potencialmente severa $(3,5)$. A utilização de antibióticos pode somar uma maior toxicidade em um período onde o paciente se recupera do tratamento com drogas de conhecido efeito adverso. 0 custo desta estratégia com duvidosos resultados práticos encarece 0 procedimento e pode inviabilizar o tratamento. Os autores observaram um aumento de colonização pelos germes Gram positivos, mas que não orientaram a escolha de antibióticos no período de neutropenia febril. 0 conhecimento do perfil microbiológico da instituição, a racionalização dos procedimentos de cuidado do paciente, testes diagnósticos mais sensíveis e métodos mais efetivos de redução do período de neutropenia poderão reduzir a necessidade de utilização deste tipo de prática. 
M icrobiological profileof patientsin thefirst third dayspost bonemarrow transplantation of theT ransplantation Servicein SantaC asa, Sao Paulo

Flávio A. Naoum, Larissa T. V. Martins

Nelson S. Castro, José C. Barros, Carlos S.

Chiattone

\section{Abstract}

The bacterial infections remain one of the most common causes of morbidity and mortality among bone marrow transplantation patients. During the neutropenic period these patients are more susceptible to acquire these agents. The improvement on antibiotic prophylaxis has changed the bacterial spectrum on the last decade. Surveillance cultures have been strategically used as a method to foresee an agent that potentially increases morbidity at this time of treatment. However it is also criticized due to its low sensitivity and specificity. Theauthors retrospectively reviewed the surveillance cultures on the first thirty days of 50 patients who underwent bone marrow transplantation at Santa Casa de São Paulo BMT unit. The male patients were $62 \%$ and the prevalent age ranging 21 to 40 years. The allogeneic transplant and peripheral blood stem cell infusion were $68 \%$ and $72 \%$ respectively. Chronic myelogenous leukemia was the most transplanted disease. Gram-positive isolates were found on $64 \%$ of all cultures. The Gram-positive agents were prevalent on skin, nostril swabs and also on catheter exit sites, while gram negative agents were isolated on oropharynx and anal swabs. There was no relation either on a positive blood culture test or a antibiotic prophylaxis regarding the surveillancecultures when retrospectively reviewed during these first days of treatment.

Rev.bras.hematol.hemoter.,2002,24(2):91-96

Keywords: Bone marrow transplantation, surveillance cultures, infection

\section{Referências Bibliográficas}

1. Sable CA, Donowitz GR. Infections in bone marrow transplant recipients. C lin I nfect D is 1993; 18:273-84.

2. Schimpff SC. Surveillance cultures. J I nfect $D$ is 1981; 144:81-4.

3. Riley DK, Pavia AT, B eatty PG. Surveillance cultures in bone marrow transplant recipients: worthwhile or wasteful ? Bone M arrow T ransplant 1995; 15:469-73.

4. Buckner CD, Clift RA, Sanders JE. Protective enviroment for marrow transplant recipients. Ann Intern M ed 1978; 89:893-901.

5. Czirók $E$, Prinz GY, Dénes R. Value of surveillance cultures in a bone marrow transplantation unit. J M ed Microbiol 1997;46: 785-91.

6. Woo PCY, Wong SSY, Lum PNL. Cell-walldeficient bacteria and culture-negative febrile episodes in bone-marrow-transplant recipients. Lancet 2001; 357:675-9.

7. Klatersky J. Science and pragmatism in the treatment and prevention of neutropenic infection. J. Antimicrob Chemother. 1998; 41, Suppl. D, 13-24.

8. Viscoli C, et al. Gram-Positive Bacteremia in Granulocytopenic Cancer Patients, EORTC International Antimicrobial Therapy Cooperative Group. Eur J Cancer 1990; 26, 5: 569-574.

9. Oppenheim BA. The changing pattern of infection in neutropenic patients. JAC. 1998; 41suppl D, 7-11.

10. Hughes WT, et al. Guidelines for the use of Antimicrobial Agents in Neutropenic Patients with Unexplained Fever from Infectious Disease Society of America. J Infect D is 1990; 161: 381-396.

Recebido - 09/04/2002

Aceito - 08/06/2002 